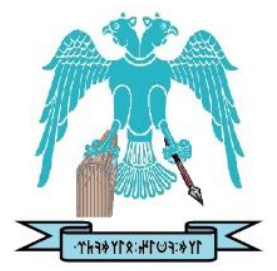

JOURNAL OF ENERGY SYSTEMS

2022, 6(1)

\title{
Effect of position of heat flux profile on the absorber surface of parabolic trough solar collector for direct steam generation
}

\author{
Ram Kumar Pal (it) \\ Indian Institute of Technology Delhi, Center for Energy Studies, New Delhi, India-110016, rkpaliitd@gmail.com \\ K. Ravi Kumar (D) \\ Indian Institute of Technology Delhi, Center for Energy Studies, New Delhi, India-110016, krk@ces.iitd.ac.in
}

\begin{abstract}
The overall performance of parabolic trough solar collector (PTSC) based power plants could be improved by introducing the Direct steam generation (DSG) in the receiver of the solar collector. However, the thermalhydraulic instability induced in the DSG process is a severe issue for the commercial application of the technology. The concentrated solar flux falling on the dry portion of the absorber before or after solar noon generates a high circumferential thermal gradient in the stratified flow region. In this work, numerical analysis of thermo-hydrodynamics of DSG has been performed to study the effect of position of solar flux profile using CFD solver ANSYS Fluent 2020R1. The TPF in the solar collectors is modeled through two-fluid modeling approach. The inlet mass flow rate and operating pressure for PTSC are considered as $0.6 \mathrm{~kg} / \mathrm{s}$, and $100 \mathrm{bar}$, respectively. The solar beam radiations are considered as $750 \mathrm{~W} / \mathrm{m} 2$ and $1000 \mathrm{~W} / \mathrm{m} 2$. The obtained results revealed that temperature distribution at the absorber outer surface varies in the range of $585 \mathrm{~K}$ to $643 \mathrm{~K}$. The maximum circumferential temperature difference is observed as $55.5 \mathrm{~K}$. The volume fraction of vapor at the absorber outlet are found as 0.31 and 0.37 respectively for DNI $750 \mathrm{~W} / \mathrm{m} 2$ and $1000 \mathrm{~W} / \mathrm{m} 2$. The corresponding pressure losses are $316 \mathrm{~Pa}$ and $350 \mathrm{~Pa}$, respectively. The obtained results could be employed to characterize the thermal behavior of the DSG solar collectors. The model is useful to configure the solar field operation for optimum performance.
\end{abstract}

Keywords: Concentrated solar power, Direct steam generation, Parabolic trough solar collector, Thermal-hydraulic modeling, Two-fluid modeling

Cite this paper $\mathrm{Pal}, \mathrm{RK}, \&$ Kumar, KR., Effect of position of heat flux profile on the absorber surface of parabolic as: trough solar collector for direct steam generation. Journal of Energy Systems 2022; 6(1): 46-61, DOI: $10.30521 /$ jes. 952658

(c) 2022 Published by peer-reviewed open access scientific journal, JES at DergiPark (https://dergipark.org.tr/en/pub/jes)

\begin{tabular}{|c|c|c|c|}
\hline Nomenclature & & & \\
\hline AIS & Absorber inner surface & $F_{t d}$ & Turbulent dispersion force $(\mathrm{N})$ \\
\hline AOS & Absorber outer surface & $F_{v m}$ & Virtual mass force $(\mathrm{N})$ \\
\hline CFD & Computational Fluid Dynamics & $F_{w l}$ & Wall lubrication force $(\mathrm{N})$ \\
\hline CTD & Circumferential temperature difference & $q$ & Gravitational acceleration $\left(\mathrm{m} / \mathrm{s}^{2}\right)$ \\
\hline DISS & Direct solar steam & $H$ & Specific enthalpy $(\mathrm{J} / \mathrm{kg})$ \\
\hline DNI & Direct Normal Irradiance $\left(\mathrm{W} / \mathrm{m}^{2}\right)$ & $H_{h t}$ & Interfacial heat transfer coefficient $\left(\mathrm{W} / \mathrm{m}^{2}-\mathrm{K}\right)$ \\
\hline DSG & Direct steam generation & $L H$ & Latent heat $(\mathrm{J} / \mathrm{kg})$ \\
\hline HEM & Homogeneous equilibrium model & $\dot{m}$ & Mass transfer rate $(\mathrm{kg} / \mathrm{s})$ \\
\hline HTF & Heat transfer fluid & $p$ & Pressure $(\mathrm{Pa})$ \\
\hline EMM & Eulerian Multiphase Model & $\dot{q}$ & Heat flux $\left(\mathrm{W} / \mathrm{m}^{2}\right)$ \\
\hline ID & Inner diameter & $Q$ & Interphase heat transfer $\left(\mathrm{W} / \mathrm{m}^{2}\right)$ \\
\hline FVM & Finite volume method & $R$ & Phase interaction \\
\hline HTC & Heat transfer coefficient $\left(\mathrm{W} / \mathrm{m}^{2}-\mathrm{K}\right)$ & $T$ & Temperature (K) \\
\hline MT & Mass transfer & $v$ & Velocity $(\mathrm{m} / \mathrm{s})$ \\
\hline MFR & Mass flow rate $(\mathrm{kg} / \mathrm{s})$ & Greek Letters & \\
\hline PRESTO & PREssure STaggering Option & $\mu$ & Dynamic viscosity $\left(\mathrm{N}-\mathrm{s} / \mathrm{m}^{2}\right)$ \\
\hline PTSC & Parabolic Trough Solar Collector & $\alpha$ & Phase volume fraction \\
\hline RPI & Rensselaer Polytechnic Institute & $\theta$ & Angle (degree) \\
\hline SHF & Solar heat flux $\left(\mathrm{W} / \mathrm{m}^{2}\right)$ & $\rho$ & Density $\left(\mathrm{kg} / \mathrm{m}^{3}\right)$ \\
\hline TFM & Two-fluid model & Subscripts & \\
\hline TPF & Two-phase flow & c & Convective \\
\hline VOF & Volume of Fluid & E & Evaporative \\
\hline VVF & Vapor Volume Fraction & $F$ & Thin film \\
\hline PRESTO & PREssure STaggering Option & $i$ & Interface \\
\hline PTSC & Parabolic Trough Solar Collector & $l$ & Liquid \\
\hline Symbol & & $Q$ & Quenching \\
\hline$A$ & Area $\left(\mathrm{m}^{2}\right)$ & $v$ & Vapor \\
\hline$C_{p}$ & Specific heat capacity $(\mathrm{J} / \mathrm{kg}-\mathrm{K})$ & $w$ & Wall \\
\hline$F_{\text {lift }}$ & Lift force $(\mathrm{N})$ & $s$ & Saturation \\
\hline
\end{tabular}




\section{INTRODUCTION}

Solar energy could be considered as the most promising renewable energy source and have the potential to replace fossil fuels used in conventional thermal power plants $[1,2]$. Most of the existing commercial PTSC power plants uses synthetic oil as heat transfer fluid (HTF) [3,4]. The heat from the HTF is transferred to the water to generate steam using heat exchanger to drive the turbine and is shown in Fig. 1 (a) [5]. The solar thermal power plants are mainly composed of three subsystems: solar field, steam generators (heat exchangers) and power block. In case of DSG process, the water/steam is used as working fluid in the solar field as well as power block. The steam is generated in the solar field by preheating, evaporation, and superheating the working fluid [6,7]. The removal of steam generators makes the plants configuration simple and lowers the investment cost (see Fig. 1 (b)). The current DSG technology could generate steam around $500-550^{\circ} \mathrm{C}[8,9]$. The steam at higher temperature improves Rankine cycle efficiency. This improves the performance of the solar thermal power generation systems and reduce the capital as well as operational and maintenance cost [10]. Further, water/steam is nonpollutant in nature and any possible leakage does not cause fire or environmental issues. The technical and commercial feasibility of DSG based PTSC power plants have been proved in the European DISS project [11]. The first commercial DSG solar power plant is installed in Thailand named TSE-1. The capacity of TSE-1 is 5 MWe [12]. In the DSG process, the steam parameters are bounded by design limitations of solar field components at high pressure and temperature as well as absorber wall thermal gradients, absorber coatings, and materials cost [9].



(a)

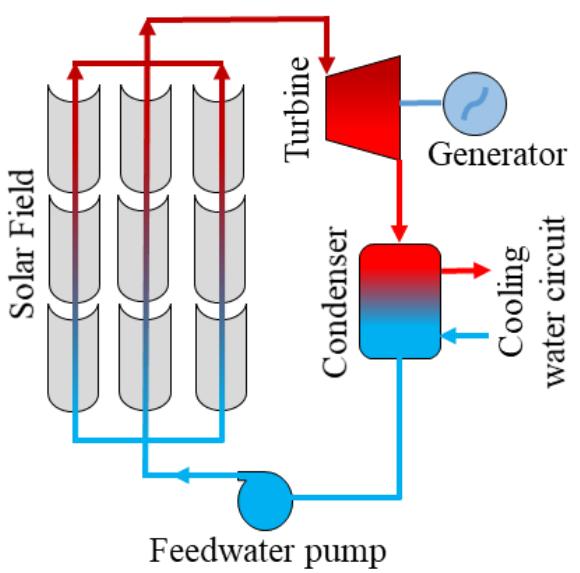

(b)

Figure 1. Schematic of PTSC power plant: (a) oil-based plant and (b) DSG plant [13].

The PTSC components need to be designed to withstand the higher temperature and pressure. Further, the steam with constant defined properties at the turbine inlet is required for stable operation of the power block. The steam at the turbine inlet could be varied quantitatively, not qualitatively. High-density difference of the water and steam consequences uneven two-phase flow (TPF) in the solar collectors. The various types of TPF patterns may exist in the receiver [13-15]. The quantity and quality of steam at the solar field outlet depends on the inlet flow conditions and solar radiation. The incoming solar radiation does not remain constant throughout the day and not controllable. The variation in the impinging solar radiation on the receiver surface changes the preheating, evaporation, and superheated section length. Increment in flow velocity also provoke flow instability. The above discussed thermalhydraulic instability induced in the absorber of the solar collectors is a severe issue in the commercial application of the technology. The control of flow conditions is a way to control the DSG process in the solar collectors. The flow control mechanism is required to install at the inlet of each row of solar field to avoid the instability associated with the DSG process. The development of accurate flow control mechanism for solar field is essential to deliver the steam to power block at constant properties. 
The modeling of TPF with phase change is complex task due to the lack of complete knowledge, associated physics and unavailability of empirical two-phase correlations. The various TPF models have been introduced in the literature such as homogeneous, two-fluid, drift, and heterogeneous models [16]. Various software such as ATHLET, RELAP; and inhouse codes such as FORTRAN, Matlab, and Modelica are implemented for DSG modeling. Commercial CFD tools such as ANSYS Fluent and STAR-CCM+ are also implemented for the thermal-hydraulic assessment of DSG process. Wang et al. [17] examined the heat transfer enhancement using metal foams. The effect of layout, geometrical parameters, and porosity have been investigated. The homogeneous equilibrium multiphase model of STAR-CCM+ computed pressure drops with accuracy within 10\% [18]. Pal and Kumar [15] investigated the circumferential temperature distribution, pressure drop, and VVF using Eulerian TFM. Li et al. [19] developed an improved SIMPLE algorithm to realize the transient characteristics of the DSG process in once through solar collector rows. Hosseinalipour et al. [20] incorporated twisted tape in superheated section and found that circumferential temperature reduced in the range of 10-45\% while the friction factor increased in the range 1.8-4.1 times. The Comprehensive review of thermal-hydraulic modeling of DSG and available modeling tools is presented in references [5, 21].

The homogeneous equilibrium model (HEM) approach is widely used in most of the reported thermalhydraulic studies [5, 22]. The accuracy of HEM model is limited as it is modeled theoretically as single phase considering the average properties of all the phases and many flow behaviors could not be analyzed. This model solves a single set of conservation equations. Whereas the TFM solves individual conservation equations for all phases and the DSG behavior can be analyzed more realistic and accurately $[13,23]$. Further, only a few studies have considered the solar heat flux (SHF) distribution at the absorber outer surface (AOS) as non-uniform [24]. In these studies, the SHF profile corresponding to solar noon was considered on the AOS [21]. However, the distribution of the concentrated SHF at the AOS changes with the time of the day [25]. The concentrated SHF falling on the dry portion of the absorber before or after solar noon generates a high circumferential thermal gradient in the stratified flow region. This helps to calculate the higher circumferential thermal gradient and consequently the deflection in the absorber. The present study provides insight into the DSG process's thermal-hydraulic behavior for the continuous operation of the solar field for a whole day. The SHF distributions on the AOS have been considered corresponding to the various times of the day. Further, the TFM approach is implemented to model the DSG. In the next section, the equations solved in TFM approach are described.

\section{MATHEMATICAL MODELING OF DSG}

The transport equations need to be solved to study the TPF behavior in the absorber of the PTSC. There are three multiphase models available in the ANSYS Fluent: volume of fluid (VOF), mixture, and Eulerian model. The VOF model and mixture multiphase models comes under HEM approach, whereas the Eulerian model is based on the TFM approach [26]. The TFM approach is relatively more computationally expensive but has better accuracy as compared to the HEM approach. In this study, the Eulerian multiphase model (EMM) is used to study the liquid-vapor TPF in the solar collectors. The separate transport equations have been solved for each phase. Here six conservation equations have been solved; three for liquid and three for vapor. The solved governing equations are discussed below.

\subsection{Governing Equations}

The mass transport equation for liquid is described as follows [27]:

$$
\frac{\partial}{\partial t}\left(\alpha_{l} \rho_{l}\right)+\nabla \cdot\left(\alpha_{l} \rho_{l} \vec{v}_{l}\right)=\left(\dot{m}_{v l}-\dot{m}_{l v}\right)
$$


Here, the subscripts $l$ and $v$ represent the liquid and vapor, respectively. The terms $\rho$ and $v$ are the density and velocity of the fluid; $\dot{m}$ is the mass transfer (MT) rate from one phase to another phase.

The momentum transport equation for liquid is described as [27]:

$$
\begin{aligned}
\frac{\partial}{\partial t}\left(\alpha_{l} \rho_{l} \vec{v}_{l}\right)+\nabla & \cdot\left(\alpha_{l} \rho_{l} \vec{v}_{l} \vec{v}_{l}\right) \\
& =-\alpha_{l} p+\nabla \cdot \overline{\bar{\tau}}_{l}+\left(\vec{R}_{v l}+\dot{m}_{v l} \vec{v}_{v l}-\dot{m}_{l v} \vec{v}_{l v}\right)+\alpha_{l} \rho_{l} \vec{g} \\
& +\left(\vec{F}_{v m, l}+\vec{F}_{l i f t, l}+\vec{F}_{t d, l}+\vec{F}_{w l, l}\right)
\end{aligned}
$$

Here, $\mathrm{p}$ is the pressure shared by both phases; $\vec{F}_{v m, l}, \vec{F}_{l i f t, l}, \vec{F}_{w l, l}$ and $\vec{F}_{t d, l}$ are the liquid-vapor interaction forces. In Eq. [2] the term $\overline{\bar{\tau}}_{l}$ represents the stress-strain tensor.

The energy transport equation for liquid is described as [27]:

$$
\frac{\partial}{\partial t}\left(\alpha_{l} \rho_{l} H_{l}\right)+\nabla \cdot\left(\alpha_{l} \rho_{l} \vec{v}_{l} H_{l}\right)=\alpha_{l} \frac{\partial p_{l}}{\partial t}+\overline{\bar{\tau}}_{l}: \nabla \vec{v}_{l}-\nabla \vec{q}_{l}+\left(Q_{v l}+\dot{m}_{v l} H_{v l}-\dot{m}_{l v} H_{l v}\right)+S_{l}
$$

Here, the term $H_{l}, \vec{q}_{l}, Q_{v l}$, and $S_{l}$ represents specific enthalpy, heat flux vector, interphase heat transfer, and energy source, respectively. The conservation equations for the vapor phase could be defined in a similar way as Eqs. [1-3].

\subsection{Phase Change Model}

There is the MT from the liquid to the vapor due to the boiling. The total MT rate is the contribution of MT at the absorber inner surface (AIS) and at the interface of the liquid-vapor. The total MT is defined as [27]:

$$
\dot{m}_{l v}=\frac{\left(T_{l}-T_{s}\right) H_{h t} A_{i}}{L H+C_{p, l}\left(T_{s}-T_{l}\right)}+\frac{\dot{q}_{E} A_{\text {cell }}}{L H+C_{p, l}\left(T_{s}-T_{l}\right)}
$$

Here, the terms $T_{l}$ and $T_{s}$ represents the liquid and saturation temperature, respectively; $H_{h t}$ is the interfacial heat transfer coefficient (HTC) and calculated by Ranz and Marshall [28] formulation; $A_{i}$ and $A_{\text {cell }}$ are interfacial area density and cell face area, respectively; $L H$ is the latent heat; $C_{(p, l)}$ is the liquid specific heat.

\subsection{Boiling Heat Transfer Model}

The modified RPI boiling model is implemented to calculate the boiling HT. The SHF at the AOS is split into five parts (as shown in Eq. [5]) based on the method of heat exchange between the heated surface and fluid [27].

$$
\dot{q}_{w}=\left(\dot{q}_{c}+\dot{q}_{Q}+\dot{q}_{E}+\dot{q}_{F}\right) f\left(\alpha_{l}\right)+\left\{1-f\left(\alpha_{l}\right)\right\} \dot{q}_{v}
$$

Here, $\dot{q}_{w}$ is the SHF applied at the absorber outer wall. $\dot{q}_{c}, \dot{q}_{Q}, \dot{q}_{E}, \dot{q}_{F}$, and $\dot{q}_{v}$ are convective HT to liquid, quenching HT, evaporative HT, thin film boiling HT, and convective HT to vapor, respectively. The term $f\left(\alpha_{l}\right)$ is calculated from a formula developed by Tentner et al., [29].

\subsection{Methodology}

The thermal-hydraulic simulations are performed for steady-state conditions. The Eulerian multiphase model is used to model the DSG in PTSC. This model is based on the TFM approach. The governing 
equations for modeling of DSG are described in the section 2. Following assumptions have been made in this study:

(a) The fluid is Newtonian.

(b) The thermophysical properties of fluid are constant.

(c) The fluid is isotropic and homogeneous.

(d) The flow is incompressible.

(e) Viscous energy dissipation is neglected.

(f) The flow is steady.

(g) Optical efficiency of solar collector is 0.8

(h) The heat loss from the absorber is neglected.

The realizable k- $\varepsilon$ turbulence model has been implemented to model the effect of turbulence on fluid flow and HT. The governing equations are discretized using finite volume method (FVM) in ANSYS Fluent software. The solver type used for numerical simulation is pressure-based. The spatial discretization scheme used PRESTO (PREssure STaggering Option) for pressure and first-order upwind for other parameters. The mass and energy conversation has been satisfied for all simulations. The flow chart of modeling and simulation process is shown in Fig. 2.

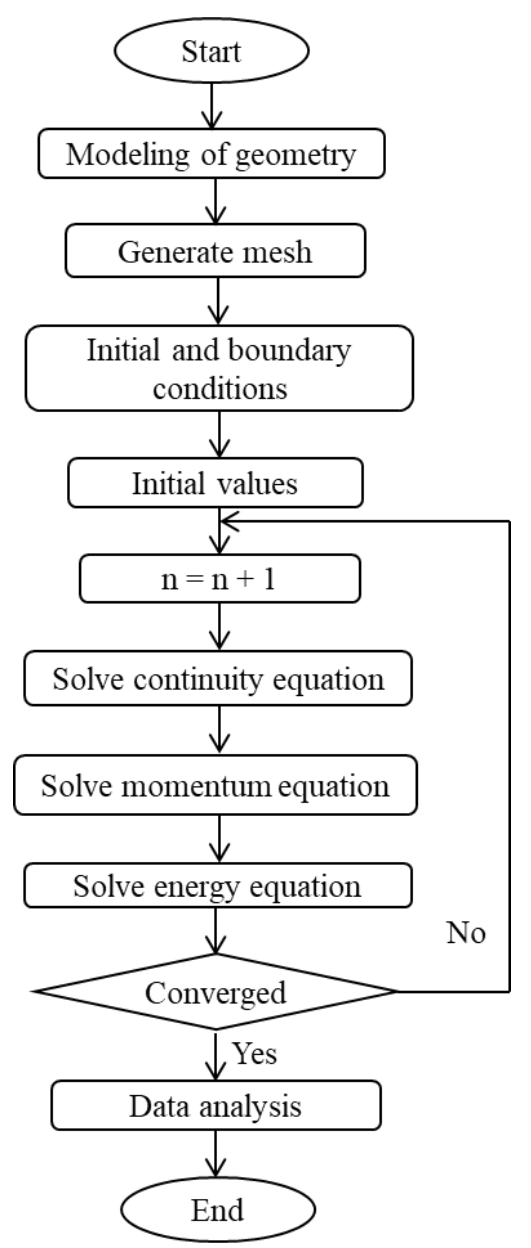

Figure 2. Flow chart for the numerical simulation of DSG in PTSC.

\subsection{Geometry and Boundary Conditions}

In this study, the LS-3 PTSC has been considered for simulation. The receiver of PTSC composed absorber tube and glass cover (envelope). The glass envelope reduces the heat losses from the receiver. In this work, $12 \mathrm{~m}$ length of absorber tube has been considered to study the thermal-hydraulics of DSG under the variable SHF around the absorber surface. The ID of stainless-steel absorber tube is $50 \mathrm{~mm}$ and OD is $70 \mathrm{~mm}$. The schematic of the geometry and inlet-outlet boundary conditions are described in 
Fig. 3. The inlet MFR and operating pressure for PTSC are considered as $0.6 \mathrm{~kg} / \mathrm{s}$, and $100 \mathrm{bar}$, respectively. Fluid is considered as saturated liquid at the absorber inlet.
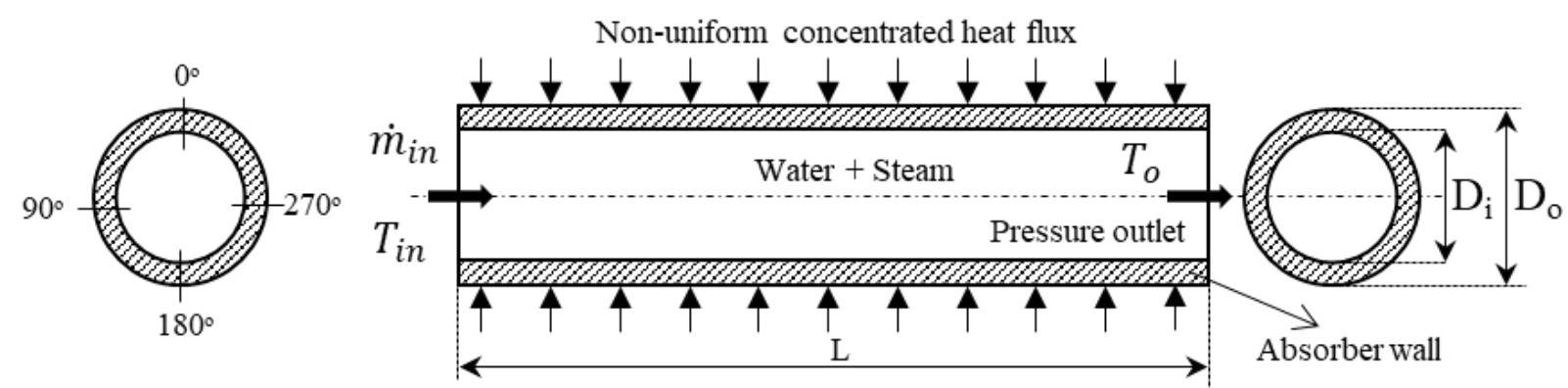

Figure 3. Schematic of the geometry and boundary conditions.

The solar collectors rotate around its axis to make the incoming radiation normal to the aperture plane of the concentrator. Hence, the distribution of SHF at the AOS varies throughout the day. The characteristic of distribution of the SHF remains almost symmetric before and after solar noon if the DNI is considered as constant. In this work, the numerical simulations are performed for the DNI 750 $\mathrm{W} / \mathrm{m}^{2}$ and $1000 \mathrm{~W} / \mathrm{m}^{2}$. The equation of solar heat flux profile developed by Malan and Kumar [30] is used in this study. The optical efficiency of the PTSC is considered as 0.8. The SHF profiles around the absorber surface for solar noon and at an interval of one hour are shown in Fig. 4.

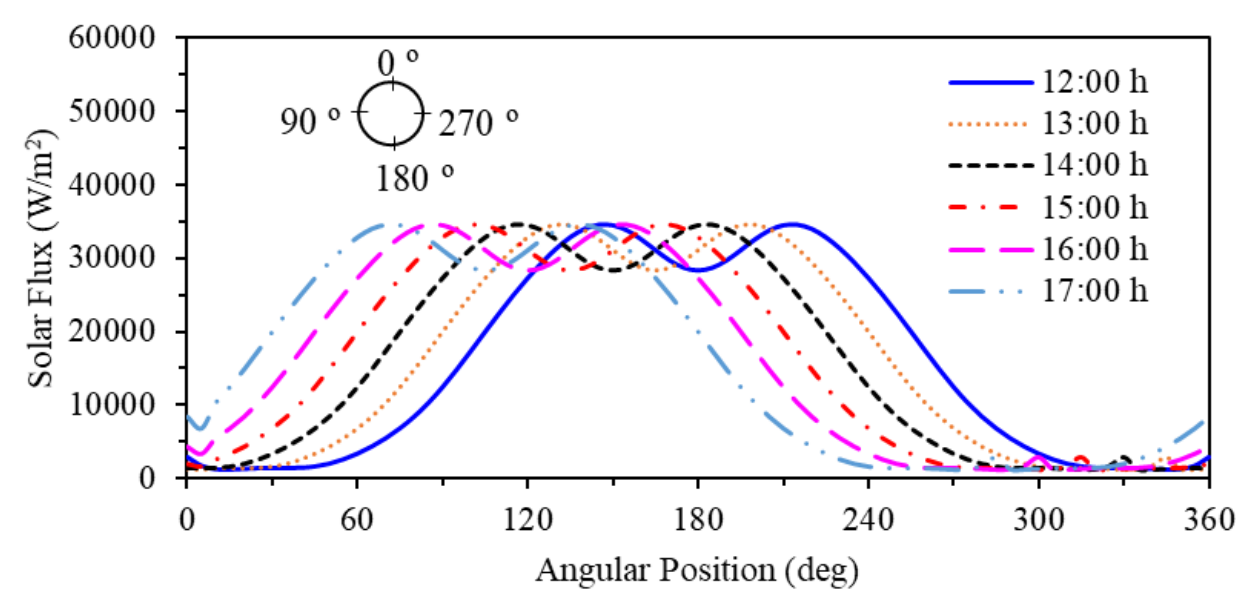

(a)

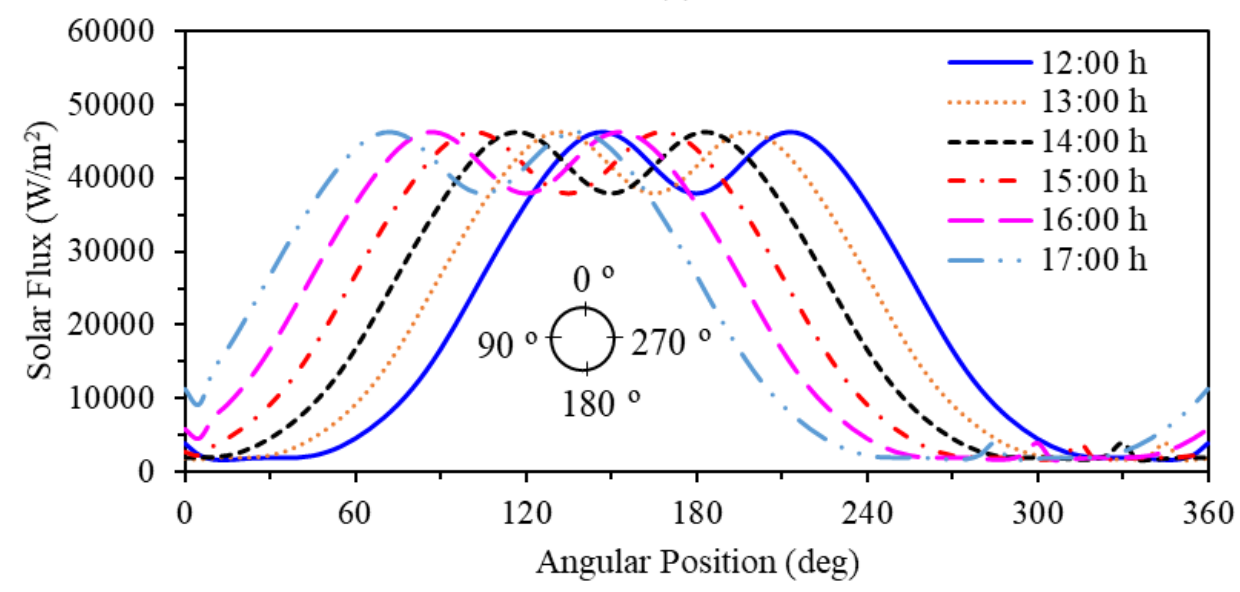

(b)

Figure 4. Distribution of SHF at the absorber outer surface for DNI: (a) $750 \mathrm{~W} / \mathrm{m}^{2}$, and (b) $1000 \mathrm{~W} / \mathrm{m}^{2}$. 

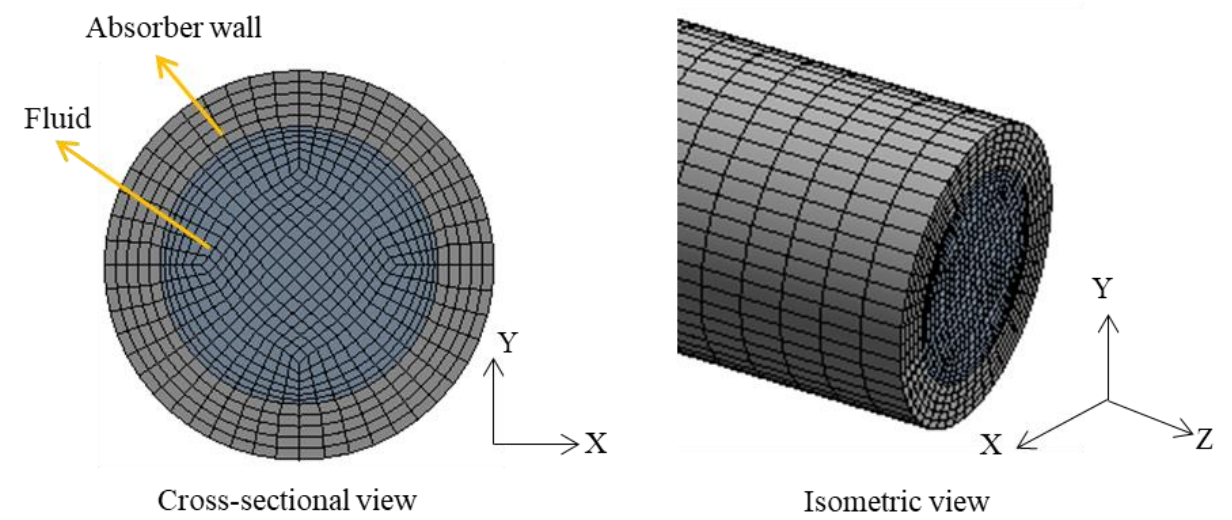

Figure 5. Structured hexahedral mesh of the geometry.

The computational domain has been developed in the ANSYS Workbench 2020R1. The structured hexahedral mesh is generated as shown in Fig. 5. The grid-independent study has been confirmed that 572460 number of cells are sufficient for numerical simulation.

\subsection{Model Validation}

The experimental results of Reynolds [31] and Bartolomei et al. [32] are used to validate the discussed TFM approach. The experimental results of Reynolds [31] are used to validate the variation of pressure along the tube length as shown in Fig. 6 (a). The length of horizontal tube was $1.8 \mathrm{~m}$, diameter $9.5 \mathrm{~mm}$. The tube was electrically heated to obtain a constant heat flux of $960 \mathrm{~kW} / \mathrm{m}^{2}$. The operating pressure, inlet mass flux, and the fluid inlet temperature were $6.86 \mathrm{bar}, 3181 \mathrm{~kg} / \mathrm{m}^{2}-\mathrm{s}$, and $381 \mathrm{~K}$ respectively. The deviation in obtained results at any axial position obtained from experimental and the present numerical work is within $0.5 \%$ (shown in Fig. 6 (a)). The deviation in the outlet fluid temperature is $0.12 \%$. The experimental and numerical results of Bartolomei et al. [32] and Maytorena and Hinojosa [33] respectively are used to validate the vapor volume fraction (VVF) distribution (shown in Fig. 6(b)) and found that the prediction of present model is close to the experimental data.

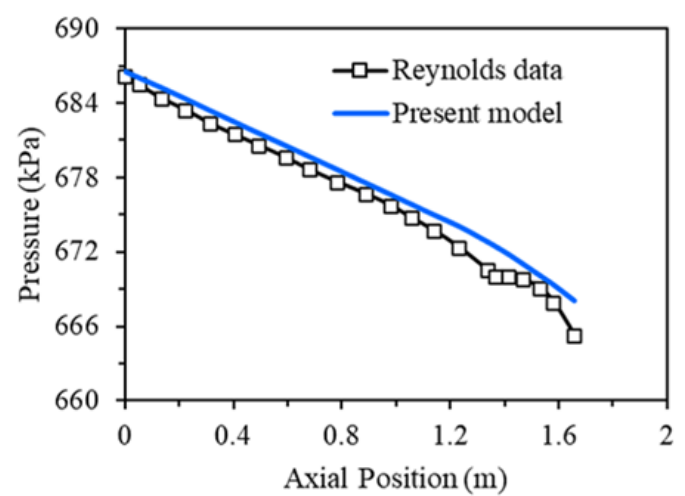

(a)

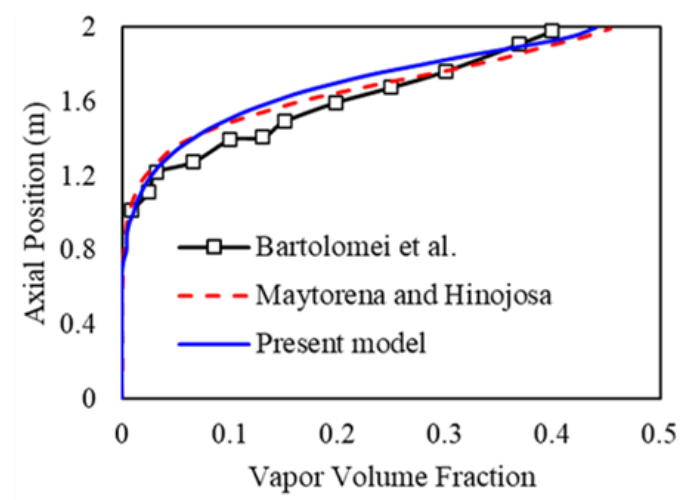

(b)

Figure 6. Validation of the present numerical model: (a) comparison of fluid pressure with Reynolds [31] data, and (b) comparison of VVF with the data of Bartolomei et al. [32] and Maytorena and Hinojosa [33].

\section{RESULTS AND DISCUSSION}

This work focused on the numerical investigation of TPF in the DSG process in the PTSC using the TFM approach. The effects of variable SHF profile on the thermal-hydraulic parameters have been investigated for DNI $750 \mathrm{~W} / \mathrm{m}^{2}$ and $1000 \mathrm{~W} / \mathrm{m}^{2}$. The distribution of SHF around the absorber surface at various times of the day is shown in Fig. 4. The schematic representation of variation of distribution in 
the SHF at the AOS throughout the day is shown in the Figs. 7(a-c). The non-uniform SHF profile and flow regimes influence the thermal distribution in the absorber wall. The high concentrated solar flux on dry portion of absorber wall before or after solar noon are critical and may induce high thermal gradient and consequently there may be possibility of deflection in the absorber. The glass envelop of the receiver may rupture if the deflection exceeds beyond the acceptable limit. Hence, it is important to find the temperature distribution. The calculation of temperature distribution by modeling approach without running the experiments save money and time. Further, insight of physical behavior of the DSG process could be visualized in more detail through numerical modeling. In this study, the numerical investigation has been performed for operating pressure and MFR of 100 bar and $0.6 \mathrm{~kg} / \mathrm{s}$ respectively. The EMM coupled with the boiling model is implemented in the ANSYS Fluent 2020R1 to perform steady-state analysis. In this section, thermal-hydraulic results for the $12 \mathrm{~m}$ length of the PTSC are discussed.

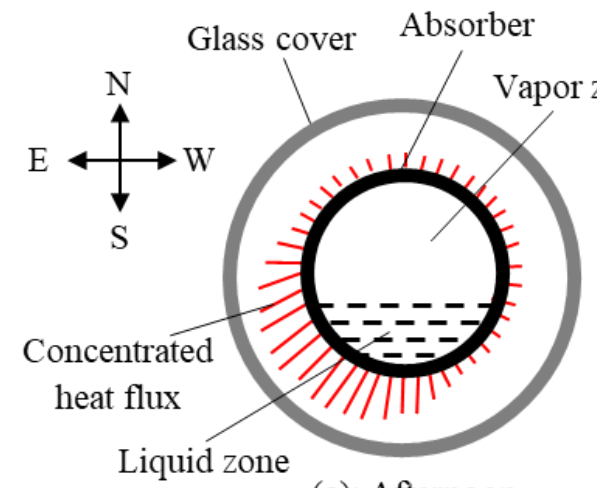

(a): Afternoon

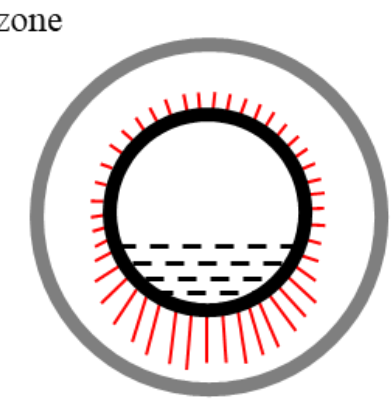

(b) Noon

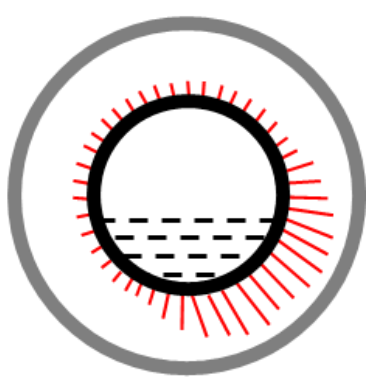

(c) Forenoon

Figure 7. Schematic representation of the variation in SHF distribution at the AOS throughout the day.

The variable SHF profile at the absorber outer surface and non-uniform HTC at the AIS has a major impact on the thermal behavior of the absorber. In DISS experimental test facility, total eight thermocouples were placed around the absorber surface to measure the circumferential temperature distribution. The position of thermocouples is shown in Fig. 8. As the time is proceeding after solar noon and high solar flux starts falling on the dry portion of the absorber, the surface temperature increasing rapidly.

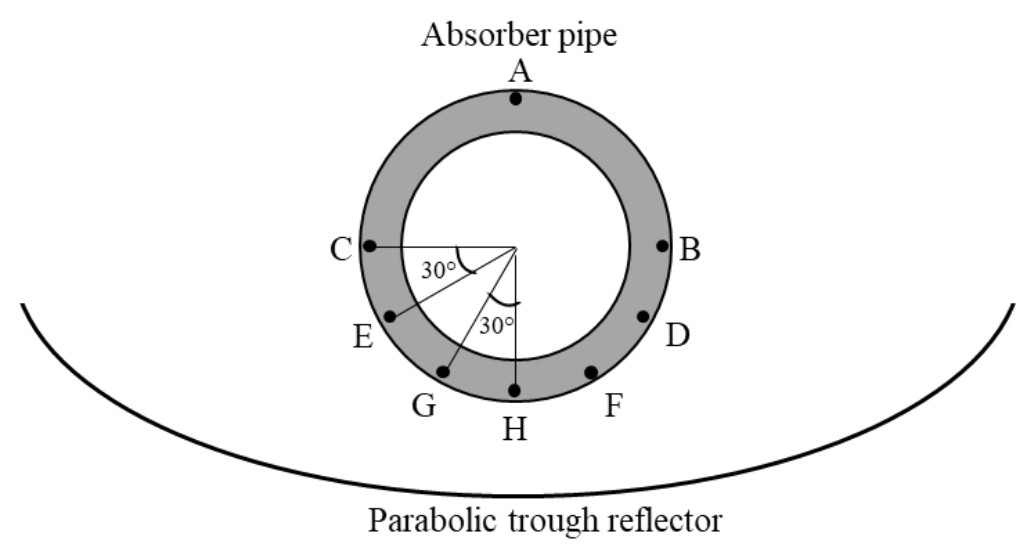

Figure 8. Position of thermocouples around the absorber surface in DISS test facility (not in scale) [34].

The temperature distribution on the AOS at various axial positions obtained from this study are presented in Figs. 9(a-f),10(a-f). The minimum and maximum absorber outer surface temperature are observed as $585 \mathrm{~K}$ to $627 \mathrm{~K}$ respectively from solar time of 12:00 h (solar noon) to 17:00 h for DNI of $750 \mathrm{~W} / \mathrm{m}^{2}$. The maximum absorber circumferential temperature difference (CTD) increases from $17 \mathrm{~K}$ to $39 \mathrm{~K}$ from $12: 00 \mathrm{~h}$ to $17: 00 \mathrm{~h}$. Similarly, the minimum and maximum absorber outer surface temperature are observed as $586 \mathrm{~K}$ to $643 \mathrm{~K}$ respectively from solar time of 12:00 h (solar noon) to 
17:00 $\mathrm{h}$ for DNI 1000 of $\mathrm{W} / \mathrm{m}^{2}$. The maximum CTD increases from $25 \mathrm{~K}$ to $55.5 \mathrm{~K}$ from 12:00 $\mathrm{h}$ to 17:00 h.

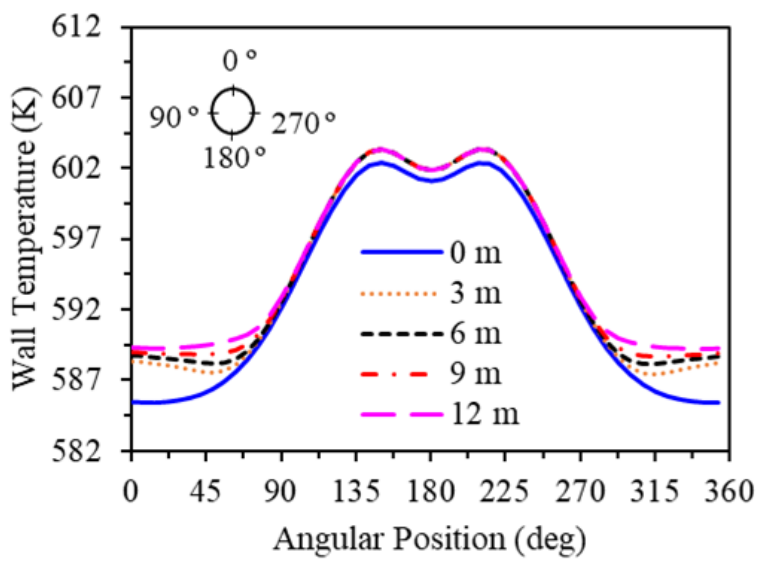

(a)

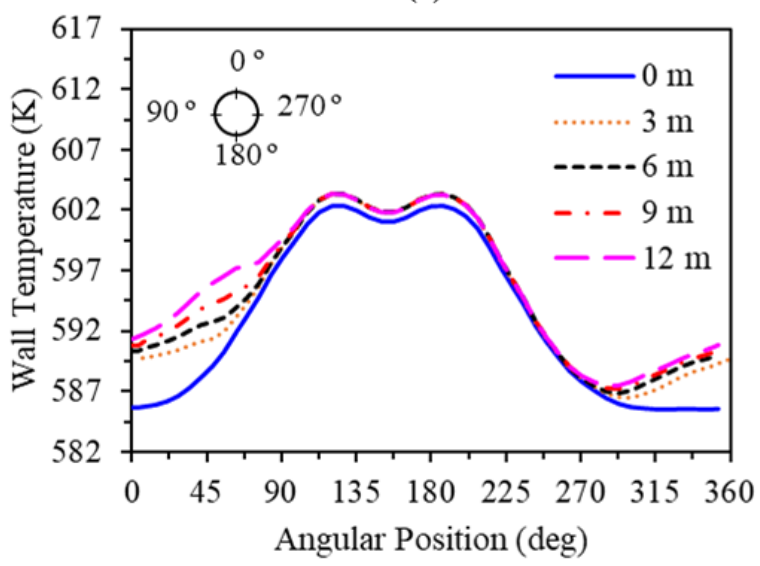

(c)

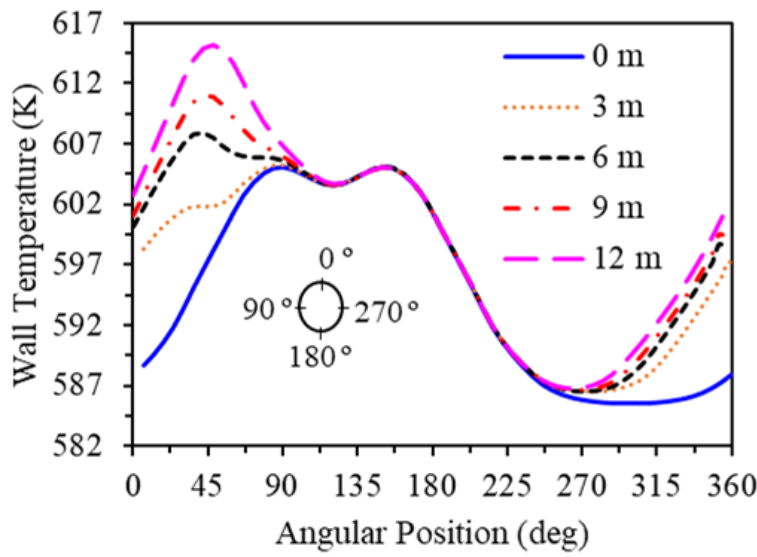

(e)

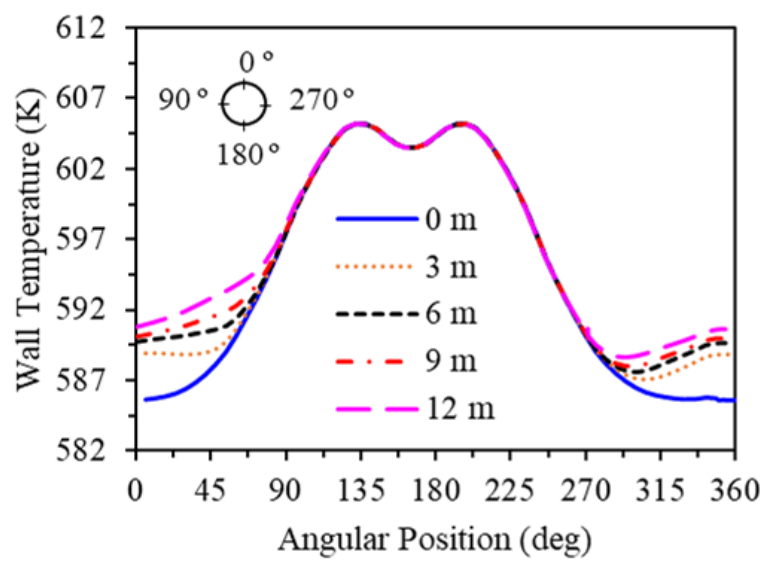

(b)

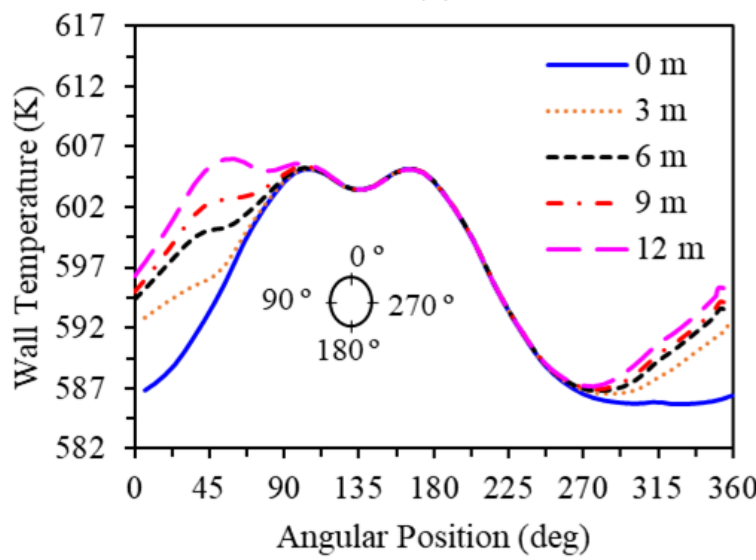

(d)

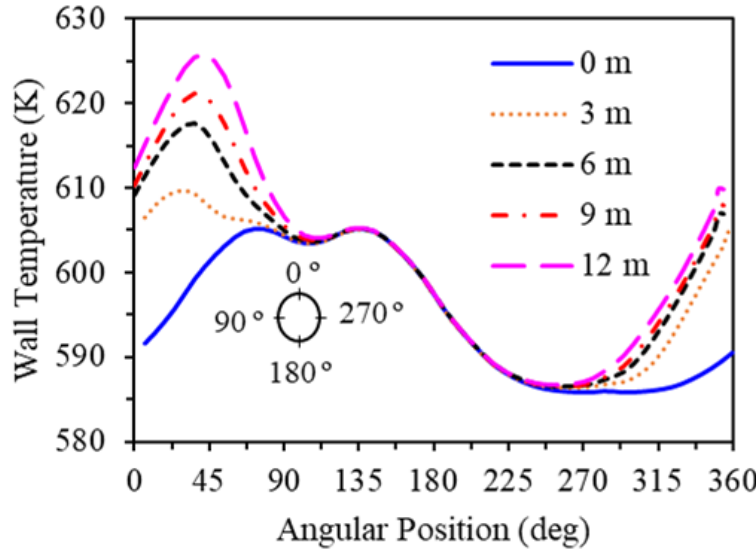

(f)

Figure 9. Temperature distribution at the AOS for DNI $=750 \mathrm{~W} / \mathrm{m}^{2}$ and heat flux profile corresponding to solar time of: (a) 12:00 h, (b) 13:00 h, (c) 14:00h, (d) 15:00 h, (e) 16:00 h, and (f) 17:00 h.

The absorber surface temperature distribution can be controlled by the inlet mass flux. There should be sufficient MFR to ensure the cooling of the absorber surface. The CTD should be within $50 \mathrm{~K}$ for the safe operation of the solar collectors. The stratified flow regime portion subjected to high risk as there is high chance to exceed the allowable limit of CTD. The experimental study has proved that tilting of absorber has positive influence on the thermal hydraulics of the DSG process. It has been tested by making the collector row by $4^{\circ}$ incline and found reduction in stratified flow regime in the flow pattern map [34]. However, this increases the investment cost. In further studies, it has been found that tilting 
of solar collector row cause only slight decrement in CTD only and not justifiable in respect of increment in the investment cost.
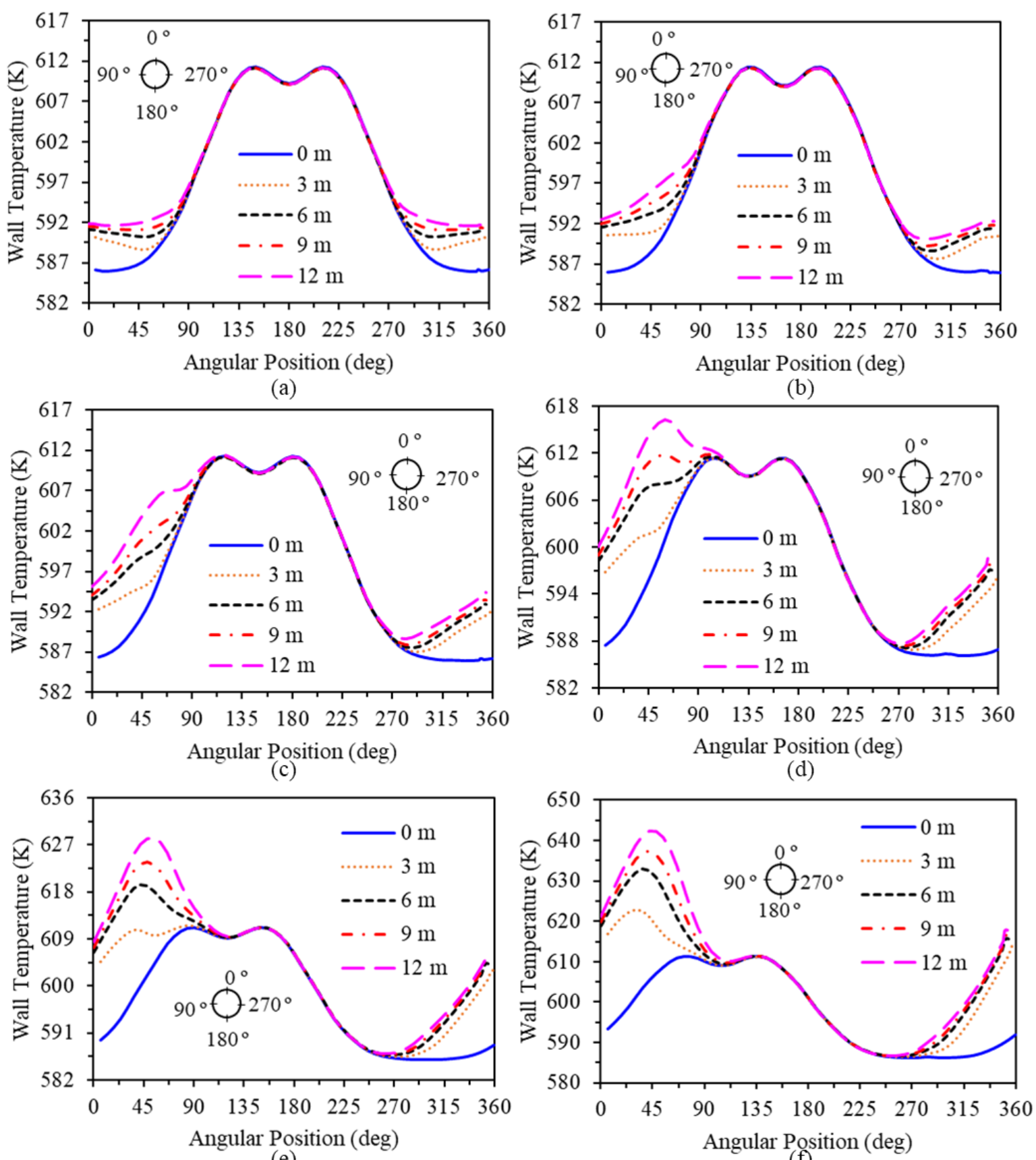

(e)

(f)

Figure 10. Temperature distribution at the AOS for DNI $=1000 \mathrm{~W} / \mathrm{m}^{2}$ and heat flux profile corresponding to solar time of: (a) 12:00 h, (b) 13:00 h, (c) 14:00h, (d) 15:00 h, (e) 16:00 h, and (f) 17:00 h.

The plots of circumferential temperature distributions help to optimize the operating conditions and consequently the development of process control mechanisms. This also required for the design improvement of the solar field components. 


\section{$\begin{array}{lllllllllll}585.0 & 588.3 & 592.6 & 596.9 & 601.2 & 605.5 & 609.8 & 614.1 & 618.4 & 622.7 & 627.0\end{array}$}

\section{Temperature (K)}
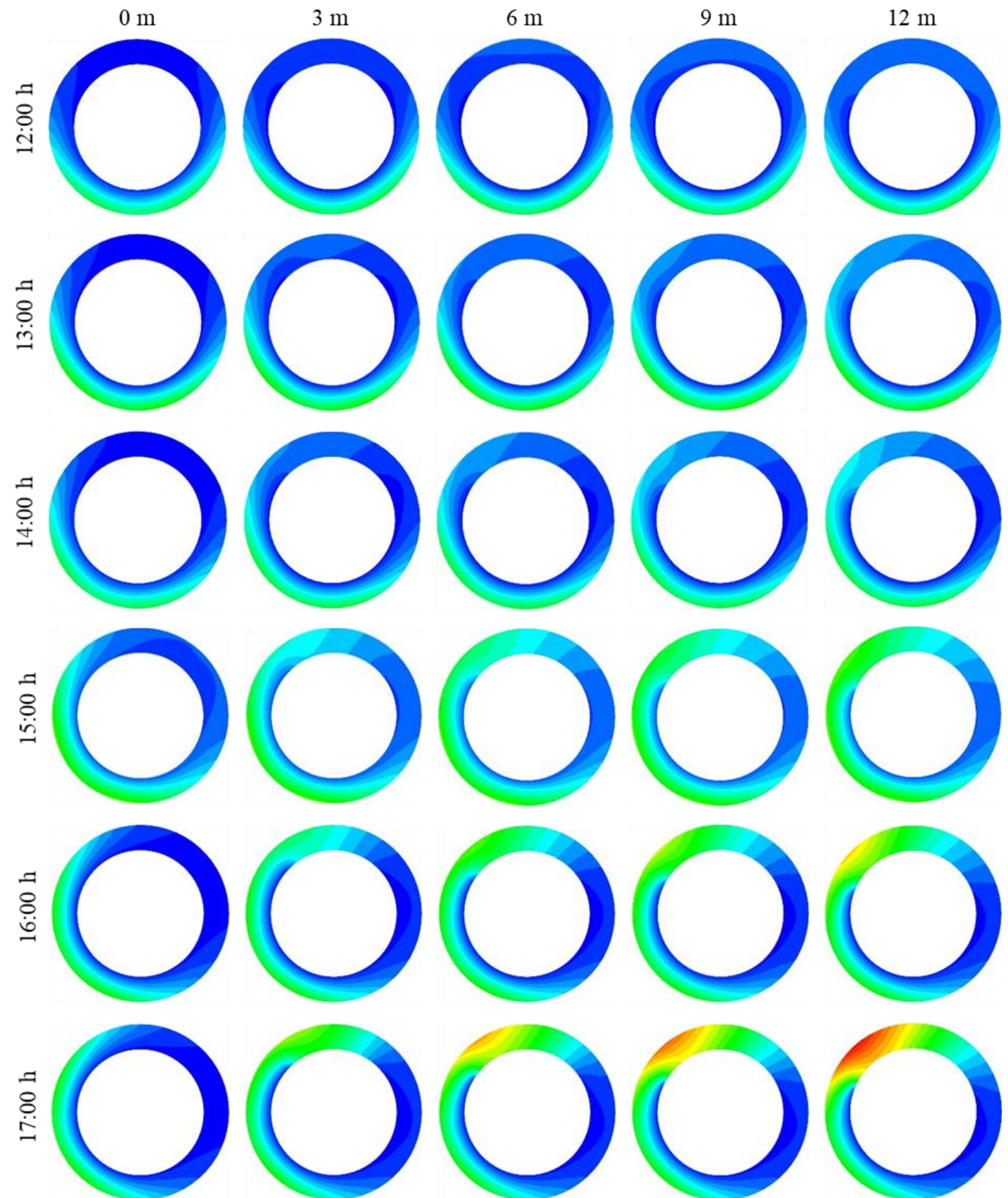

Figure 11. Contours of absorber temperature distributions at various cross-sections for beam radiation $750 \mathrm{~W} / \mathrm{m}^{2}$ and at various times of the day.

The absorber inner surface temperature depends on the fluid (liquid or vapor) in contact with the surface. There is huge difference in HTC at wetted and non-wetted portion of the absorber. The wetted part has very high HTC whereas non-wetted part has low HTC. The contours of absorber temperature distribution at various axial positions for DNI of $750 \mathrm{~W} / \mathrm{m}^{2}$ and $1000 \mathrm{~W} / \mathrm{m}^{2}$ are presented in Figs. 11 and 12 , respectively. 


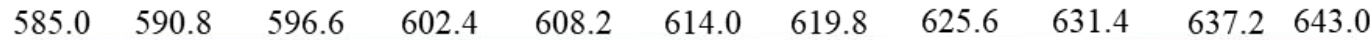

\section{Temperature (K)}

$0 \mathrm{~m}$
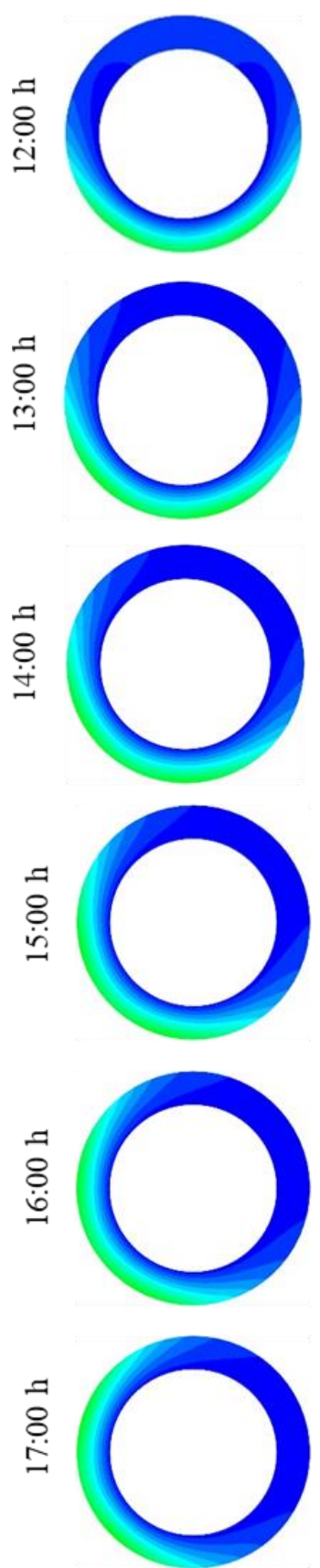

Figure 12. Contours of absorber temperature distributions at various cross-sections for beam radiation of 1000 $\mathrm{W} / \mathrm{m}^{2}$ and at various times of the day.

The portion of the AIS wetted by the liquid is at a lower temperature even there is high concentrated SHF at the outer surface. The highest heated region at the absorber outer surface moves according to the time of the day. The SHF profile on the absorber surface varies with time throughout the day as shown in Fig. 4. Further, the local position of end of evaporation is not fixed in the DSG process. The fluctuation in this position results high temperature fluctuations. This is the major challenge with once-through configuration of operation mode. In conclusion of DISS project, the recirculation mode is recommended for stable and controllable DSG process. The temperature contours are useful to determine the crosssectional temperature distribution at any local position. 
Recirculation rate is one of the important parameters for DSG solar field operation. The high recirculation rate guaranty high local cooling of the absorber. However, high recirculation rate results high pressure loss and consequently high parasitic power consumptions. Hence, the calculation of minimum recirculation rate concerning the sufficient cooling of the absorber is desirable. The local position of recirculation also depends on VVF at the concerned location. The variation of VVF along the solar collector row helps to decide the position of installation of water-steam separator for recirculation. The variations of VVF under the considered operating conditions are shown in Fig. 13(a,b). In this study, the DNI is considered constant and only the characteristic of SHF profile is changing due to the tracking of the PTSC system. In this case, the total heat input to the absorber remains constant. Hence, the VVFs are not changing from 12:00 h (solar noon) to 17:00 h. However, the variation of VVFs at the absorber outlet are observed as 0.31 and 0.37 respectively, for DNI $750 \mathrm{~W} / \mathrm{m}^{2}$ and 1000 $\mathrm{W} / \mathrm{m}^{2}$. The flow regimes in the solar collector row changes as the VVF increases. The annular flow is the most desirable flow as it provides the highest cooling of the absorber.

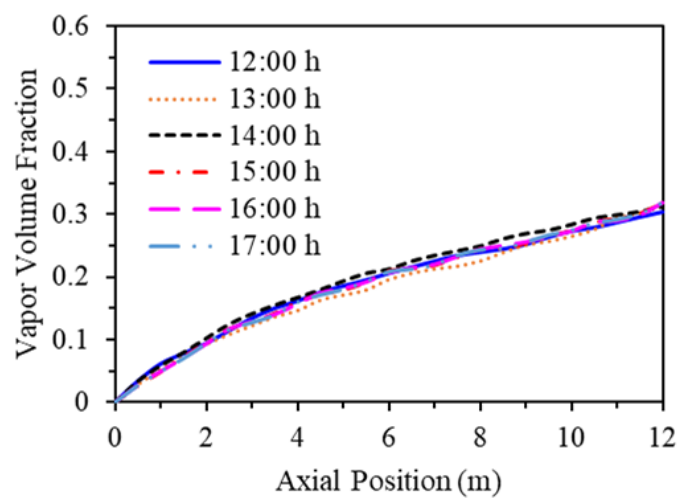

(a)

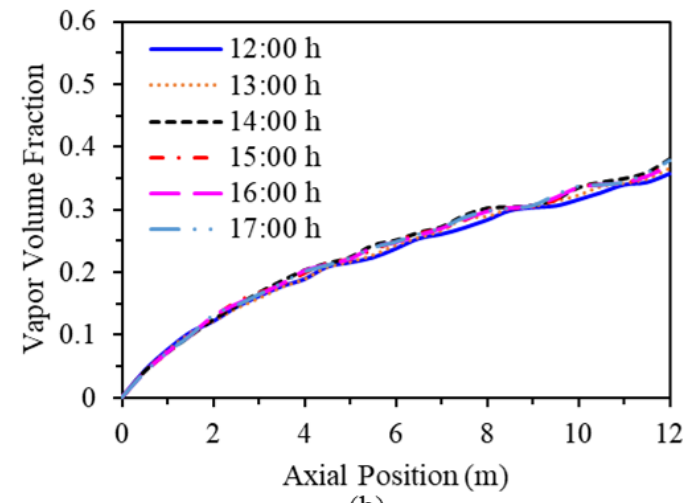

(b)

Figure 13. Variation of VVF along the absorber length for beam radiations of (a) $750 \mathrm{~W} / \mathrm{m}^{2}$ and (b) $1000 \mathrm{~W} / \mathrm{m}^{2}$.

As the VVF increases along the flow direction, the fluid mixture velocity increases. There is pressure loss due to an increment in the fluid velocity. The pressure loss also happens due to the boiling of the liquid. In case of DSG process in the solar collectors, the pressure drop is dominated by pressure loss in the TPF section. This increases the pumping power. However, the parasitic power consumption in feed pump due to pressure loss in the DSG process is affordable. The pressure loss along the absorber length is presented in Fig. 14(a,b).

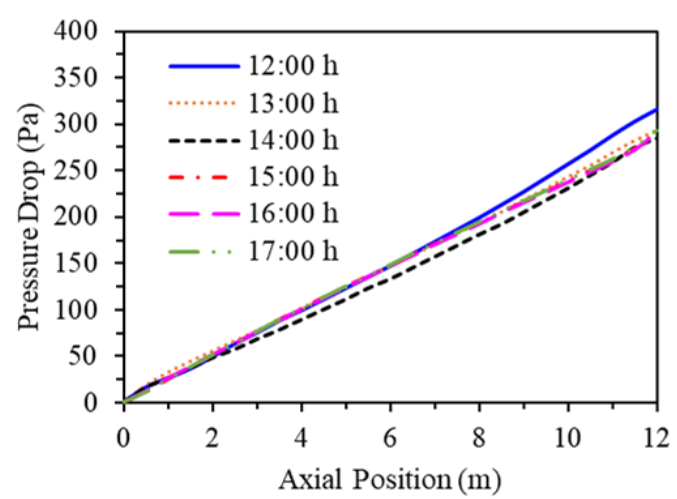

(a)

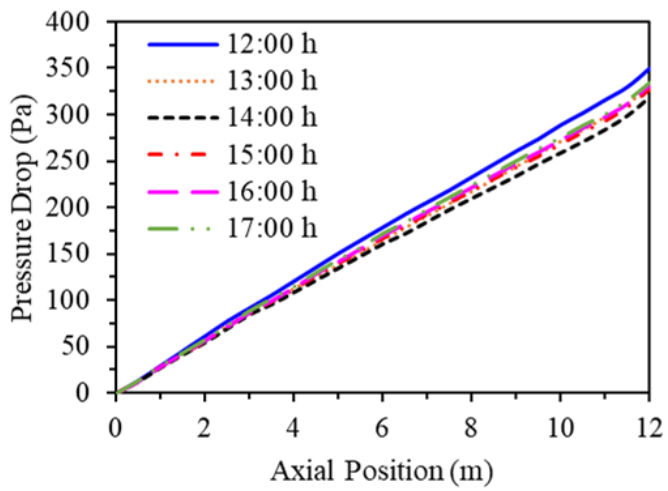

(b)

Figure 14. Pressure loss along the absorber length for beam radiations of (a) $750 \mathrm{~W} / \mathrm{m}^{2}$, and (b) $1000 \mathrm{~W} / \mathrm{m}^{2}$.

The maximum pressure loss is observed at the solar noon. The corresponding pressure losses are $316 \mathrm{~Pa}$ and $350 \mathrm{~Pa}$, respectively, for DNI $750 \mathrm{~W} / \mathrm{m}^{2}$ and $1000 \mathrm{~W} / \mathrm{m}^{2}$ in $12 \mathrm{~m}$ length of the PTSC. The results reveal that as DNI increases, the pressure loss in the solar collectors increases. Similar results have been found in sensitivity analysis of DSG process in PTSC conducted by Lobón et al. [35]. The saturated water/steam temperature decrease at higher DNI due to high pressure loss. Further, the previous experimental and numerical studies have been indicated that the pressure loss decreases with operating pressure. 


\section{CONCLUSION}

The use of thermal oils in concentrated solar thermal technologies could be replaced by water/steam with introducing the DSG concept in the solar field. The overall performance of PTSC based power plants could be improved by introducing the DSG in the solar collectors. This study focused on discussion of TFM approach and its implementation for modeling of DSG in the PTSC. The Eulerian model coupled with the heat transfer model is used to model the fluid flow and boiling heat transfer. A numerical study has been performed to study the effects of variation of concentrated solar flux profile on the absorber surface with time on the thermal behavior of the absorber of the PTSC. The variation of absorber temperature, VVF, and pressure drop have been investigated. The parameters have been investigated for operation of solar field for whole day. The following major results have been observed in this study:

The absorber temperature exists between $585 \mathrm{~K}$ to $627 \mathrm{~K}$ throughout the day for DNI 750 $\mathrm{W} / \mathrm{m}^{2}$, while for DNI $1000 \mathrm{~W} / \mathrm{m}^{2}$, it varies between $586 \mathrm{~K}$ to $643 \mathrm{~K}$.

The circumferential thermal gradient is minimum at the solar noon, and it increases for solar flux profile before or after the solar noon. This is due to the presence of stratified flow and shifting of SHF profile to the top portion of the absorber. The maximum circumferential temperature difference varies between $17 \mathrm{~K}$ to $39 \mathrm{~K}$ throughout the day for DNI $750 \mathrm{~W} / \mathrm{m}^{2}$, while for DNI $1000 \mathrm{~W} / \mathrm{m}^{2}$, it varies between $25 \mathrm{~K}$ to $55.5 \mathrm{~K}$.

The VVF increases along the flow direction. The VVFs at the absorber outlet are observed as 0.31 and 0.37 , respectively, for DNI $750 \mathrm{~W} / \mathrm{m}^{2}$ and $1000 \mathrm{~W} / \mathrm{m}^{2}$.

The pressure loss increases with an increase in the DNI and vice versa. The maximum pressure loss is observed at the solar noon.

These results are useful to characterize the DSG process for operation of solar field for the whole day. The deep insight observation of thermohydraulic behavior of DSG process is useful for the development of the DSG technology. The solar field can be configured for optimum performance using the simulation results. The discussed numerical model has shown better accuracy with the experimental data and could be used to optimize the DSG process in agreement with the absorber temperature, pressure loss and DNI. Further, the model can also be used for investigation of flow boiling heat transfer systems.

\section{Acknowledgment}

The authors gratefully acknowledge the funding support by Science and Engineering Research Board (SERB), Department of Science and Technology (DST), Government of India, New Delhi (Project Number: ECR/2017/000164).

\section{REFERENCES}

[1] Samadianfard, A, Jarhan, S, Nahand, HS. Application of support vector regression integrated with firefly optimization algorithm for predicting global solar radiation. Journal of Energy Systems 2018; 2(4):180-189. DOI: $10.30521 /$ jes.458328.

[2] Li, J, Guo, H, Meng, Q, Wu, Y, Ye, F, Ma, C. Thermodynamic Analysis and Comparison of Two Small-Scale Solar Electrical Power Generation Systems. Sustainability 2020; 12:10268. DOI: 0.3390/su122410268.

[3] Idrissou, AFM, Matos, FFS, Alexandria, AR. Numerical investigation of the optical efficiency of a parabolic trough collector at different concentration ratios. Energy Sources, Part A: Recovery, Utilization, and Environmental Effects 2020; 43(21): 2755-2773. DOI: https: 10.1080/15567036.2020.1849457.

[4] Kumar, KR, Chaitanya, KVVV, Natarajan, SK. Solar thermal energy technologies and its applications for process heating and power generation - A review. Journal of Cleaner Production 2021; 282: 125296. DOI: 10.1016/j.jclepro.2020.125296. 
[5] Sandá, A, Moya, SL, Valenzuela, L. Modelling and simulation tools for direct steam generation in parabolictrough solar collectors: a review. Renewable and Sustainable Energy Reviews 2019; 113:109226. DOI: 10.1016/j.rser.2019.06.033.

[6] Pal, RK, Kumar, KR. Thermo-hydrodynamic modeling of direct steam generation in parabolic trough solar collector. In: ICAER $20197^{\text {th }}$ International Conference on Advances in Energy Research; 10-12 December 2019: Springer, Singapore: pp. 131-140.

[7] Iodice, P, Langella, G, Amoresano, A. Exergetic Analysis of a New Direct Steam Generation Solar Plant Using Screw Expanders. Energies 2020; 13:720. DOI: 10.3390/en13030720.

[8] Lugo-Leyte, R, Salazar-Pereyra, M, Torres-Aldaco, A, Lugo-Méndez, HD, Valdés-Palacios, A. Thermal Modeling of a Concentrator Pipe Composed with Direct Steam Generation. Applied Solar Energy 2012; 48(3): 212-217. DOI: 10.3103/S0003701X12030103.

[9] Willwerth, L, Feldhoff, JF, Krüger, D, Keller, L, Eickhoff, M, Krüger, J, Pandian, Y, Tiedemann, J, Succo, M, Khenissi, A. Experience of operating a solar parabolic trough direct steam generation power plant with superheating. Solar Energy 2018; 171: 310-319. DOI: https://doi.org/10.1016/j.solener.2018.06.089.

[10] Pal, RK, Kumar, KR. Modeling and simulation of direct steam generation in parabolic trough solar collector. In: TFEC 2021 5-6 $6^{\text {th }}$ Thermal and Fluids Engineering Conference; 26-28 May 2021, American Society of Thermal and Fluids Engineers, USA: pp. 1267-1276. DOI: 10.1615/TFEC2021.sol.036716.

[11] Zarza, E, Valenzuela, L, León, J, Hennecke, K, Eck, M, Weyers, HD, Eickhof, M. Direct steam generation in parabolic troughs: Final results and conclusions of the DISS project. Energy 2004; 29: 635-644. DOI: 10.1016/S0360-5442(03)00172-5.

[12] Khenissi, A, Krüger, D, Hirsch, T, Hennecke, K. Return of experience on transient behavior at the DSG solar thermal power plant in Kanchanaburi, Thailand. Energy Procedia 2015; 69: 1603-1612. DOI: 10.1016/j.egypro.2015.03.115.

[13] De Sá AB, Filho, VCP, Tadrist, L, Passos, JC. Direct steam generation in linear solar concentration: Experimental and modeling investigation - A review. Renewable and Sustainable Energy Reviews 2018; 90 : 910-936. DOI: https://doi.org/10.1016/j.rser.2018.03.075.

[14] Nisha, S, Pal, RK, Kumar, KR. Direct steam generation in parabolic trough solar collector: analytical modelling for prediction of flow pattern. AIP Conference Proceedings 2019; 2091. DOI: 10.1063/1.5096497.

[15] Pal, RK, Kumar, KR. Two-fluid modeling of direct steam generation in the receiver of parabolic trough solar collector with non-uniform heat flux. Energy 2021; 226:120308. DOI: 10.1016/j.energy.2021.120308.

[16] Soares, J, Oliveira, AC, Valenzuela, L. A dynamic model for once-through direct steam generation in linear focus solar collectors. Renewable Energy 2021; 163:246-261. DOI: doi.org/10.1016/j.renene.2020.08.127.

[17] Wang, P, Liu, DJ, Xu, C. Numerical study of heat transfer enhancement in the receiver tube of direct steam generation with parabolic trough by inserting metal foams. Applied Energy 2013; 102: 449-460. DOI: http://dx.doi.org/10.1016/j.apenergy.2012.07.026.

[18] Lobón, DH, Baglietto, E, Valenzuela, L, Zarza, E. Modeling direct steam generation in solar collectors with multiphase CFD. Applied Energy 2014; 113:1338-1348. DOI: 10.1016/j.apenergy.2013.08.046.

[19] Wang, A, Liu, J, Zhang, S, Liu, M, Yan, J. Steam generation system operation optimization in parabolic trough concentrating solar power plants under cloudy conditions. Applied Energy 2020; 265:114790.

[20] Hosseinalipour, SM, Rostami, A, Shahriari, G. Numerical study of circumferential temperature difference reduction at the absorber tube of parabolic trough direct steam generation collector by inserting a twisted tape in superheated region. Case Studies in Thermal Engineering 2020; 21:100720. DOI: 10.1016/j.csite.2020.100720

[21] Pal, RK, Kumar, KR. Investigations of thermo-hydrodynamics, structural stability, and thermal energy storage for direct steam generation in parabolic trough solar collector: a comprehensive review. Journal of Cleaner Production 2021; 127550. DOI: 10.1016/j.jclepro.2021.127550.

[22] Pal, RK, Kumar, KR. Thermo-hydrodynamic modeling of flow boiling through the horizontal tube using Eulerian two-fluid modeling approach. International Journal of Heat and Mass Transfer 2021; 168:120794. DOI: 10.1016/j.ijheatmasstransfer.2020.120794.

[23] Giglio, A, Lanzini, A, Leone, P, García, MMR, Moya, EZ. Direct steam generation in parabolic-trough collectors: A review about the technology and a thermo-economic analysis of a hybrid system. Renewable and Sustainable Energy Reviews 2017; 74: 453-473. DOI: 10.1016/j.rser.2017.01.176.

[24] Serrano-Aguilera, JJ, Valenzuela, L, Parras, L. Thermal 3D model for direct solar steam generation under superheated conditions. Applied Energy 2014; 132:370-382. DOI: 10.1016/j.apenergy.2014.07.035.

[25] Malan, A, Kumar, KR. A comprehensive review on optical analysis of parabolic trough solar collector. Sustainable Energy Technologies and Assessments 2021; 46:101305. DOI: 10.1016/j.seta.2021.101305

[26] Abedini, E, Behboudi, M, Karachi, AM, Jahromi, RH, DolatiAsl, K. Prediction of critical heat flux in flow boiling process under the effect of different operating parameters. Proceedings of the Institution of Mechanical Engineers, Part A: Journal of Power and Energy 2020; O(0):1-9. DOI: 10.1177/0957650920962231

[27] ANSYS I. ANSYS Fluent theory guide. ANSYS 18.1; 2019. 
[28] Ranz, WE, Marshal, Jr. WR. Evaporation from drops, Part 1. Chemical Engineering Progress 1952; 48: 141146.

[29] Tentner, A, Lo, S, Loilev, A, Melnikov, V, Samigulin, M, Ustinenko, V. Advances in computational fluid dynamics modeling of two-phase flow in a boiling water reactor fuel assembly. In: ICONE $200614^{\text {th }}$ International Conference on Nuclear Engineering; 17-20 July 2006: American Society of Mechanical Engineers, USA: pp. 65-72.

[30] Malan, A, Kumar, KR. Investigation of thermal performance of a large aperture parabolic trough solar collector. International Journal of Energy Research 2020; 239-244. DOI: https://doi.org/10.1002/er.6128.

[31] Reynolds, JB. Local Boiling Pressure Drop. Technical Report 1954. Argonne National Laboratory, Illinois, USA.

[32] Bartolomei, G, Brantov, V, Molochnikov, Y, Kharitonov, Y, Solodkii, V, Batashova, V, Mikhailov, V. An experimental investigation of true volumetric vapor content with subcooled boiling in tubes. Applied Thermal Engineering 1982; 29:132-135.

[33] Maytorena, VM, Hinojosa, JF. Effect of non-uniform concentrated solar flux on direct steam generation in vertical pipes of solar tower receivers. Solar Energy 2019; 183: 665-676. DOI: 10.1016/j.solener.2019.03.047.

[34] Eck, M, Zarza, E, Eickhoff, M, Rheinlander, C, Valenzuela, L. Applied research concerning the direct steam generation in parabolic troughs. Solar Energy 2003; 74:341-351. DOI: 10.1016/S0038-092X(03)00111-7.

[35] Lobón, DH, Valenzuela, L. Impact of pressure losses in small-sized parabolic-trough collectors for direct steam generation. Energy 2013; 61:502-512. DOI: 10.1016/j.energy.2013.08.049. 